Diabetologia (1994) 37: 43-48

\title{
Nerve ischaemia in diabetic rats: time-course of development, effect of insulin treatment plus comparison of streptozotocin and BB models
}

\author{
E.J.Stevens, A.L.Carrington, D. R. Tomlinson \\ William Harvey Research Institute, Department of Pharmacology, Queen Mary and Westfield College, London, UK
}

Summary This study sought to determine the timecourse of development of reduced nerve laser Doppler flux in experimental diabetes and the effect on this anomaly of insulin treatment. In addition, we aimed to compare nerve laser Doppler flux in streptozotocinand genetically-diabetic BB rat models. Sciatic nerve laser Doppler flux in diabetic rats was variable during the 2 days following streptozotocin injection; from day 4 , when the measurement was $80 \%$ of control, fluxes fell steadily and formed a plateau at $40 \%$ of control values after 4 weeks of diabetes. In a second study, using rats with 4-week streptozotocin-diabetes, sciatic nerve laser Doppler flux was reduced to $44 \%$ of the value measured in control rats. Treatment of a parallel group of diabetic rats with insulin, by sustained release implants, prevented this ischaemia, so that nerve laser Doppler flux was $91 \%$ of controls. Nerve Doppler flux in $\mathrm{BB}$ rats with 6-week genetic diabetes was $57 \%$ of a control (non-diabetic) BB group. There were no dif- ferences in mean arterial pressures between control and diabetic rats in any of the studies. Heart rates of control and insulin-treated diabetic animals were higher than those of the untreated diabetic group; in the other studies heart rates of diabetic animals were numerically lower than controls, but not significantly so. These observations suggest that sciatic nerves of rats with short-term diabetes, whether induced with streptozotocin or of genetic origin, are markedly ischaemic and that this ischaemia in streptozotocindiabetes is evident within a week of diabetes onset, forms a plateau after 4 weeks and is maintained for at least 2 months. The findings also indicate that treatment of short-term diabetes with insulin can prevent nerve ischaemia. [Diabetologia (1994) 37: 43-48]

Key words Diabetes mellitus, Doppler flux, ischaemia, rat, insulin, BB rat, streptozotocin.
Reduced nerve conduction velocity, together with exaggerated resistance to anoxia are characteristic of both experimental and clinical diabetes mellitus [1]. The development of these anomalies is associated with both poor blood glucose control and long duration of diabetes [2,3], as well as genetic and other factors [4]. The aetiology of nerve disorders is still unclear, although current hypotheses offer both biochemical and vascular explanations. The former are concerned with

Received: 22 March 1993

and in revised form: 26 July 1993

Corresponding author: Prof. D. R. Tomlinson, Department of Pharmacology, Queen Mary and Westfield College, Mile End Road, London E1 4NS, UK increased glucose flux through the polyol pathway and, thus, extensive investigation into the potential benefit of blocking aldose reductase, the first enzyme of this pathway, has been pursued. Some inhibitors have prevented conduction abnormalities in experimental diabetes, but clinical effects have been minimal (see [5] for review). Neurovascular insufficiency, leading to nerve ischaemia, has been implicated in the second group of hypotheses. This is supported by findings of reduced endoneurial nutritive flow in experimental diabetes $[6,7]$ and by low nerve oxygen tension in both diabetic animals [6] and patients [8]. Further support comes from the demonstration that maintenance of persistent central hypoxaemia in non-diabetic rats causes a nerve conduction deficit of similar magnitude to that seen in diabetic rats [9]. Pharmacological inter- 
vention aimed at improving nerve blood flow is also, therefore, rational for prevention of nerve functional abnormalities. Indeed, studies with compounds which are likely to attenuate vasoconstriction, such as guanethidine [7], lisinopril [10] and prazosin [11], have prevented slowed conduction in experimental diabetes. Treatment of diabetic rats with evening primrose oil has also attenuated these anomalies $[12,13]$, as well as preventing diabetes-induced ischaemia [14].

We have previously measured nerve laser Doppler flux (nerve blood flux) as a parameter of nerve blood flow and demonstrated a $50 \%$ reduction in streptozotocin-diabetes [14]. The present study was designed to follow the time-course of development of this abnormality and to determine the effect of treatment with insulin, delivered via sustained release implants for strict glycaemic control, on the diabetes-induced nerve blood flux deficit. We have also compared nerve blood flux in streptozotocin- and BB-diabetic rats.

\section{Materials and methods}

\section{Experimental organization}

Three separate studies are described; the first two of which used male Wistar rats (290-360 g; 9-13 weeks of age; Charles River (UK) Ltd., Margate, UK) and the third of which used BB (Biobreeding) Wistar rats (Southampton University, Southampton, UK). In the first two studies (a time-course experiment and an insulin study) diabetes was induced with streptozotocin. Rats were fasted overnight and, early the following morning, given a single intraperitoneal injection of $50 \mathrm{mg} \cdot \mathrm{kg}^{-1}$ streptozotocin (ICI Pharmaceuticals, Macclesfield, UK) freshly dissolved in sterile saline $(0.9 \%$ weight/volume aqueous $\mathrm{NaCl})$. Two days later, blood samples were obtained by tail prick from the streptozotocin-treated rats and blood glucose concentration was measured by strip-operated reflectance photometry (Reflolux, Boehringer Mannheim, Mannheim, Germany). All the animals had blood glucose concentration greater than $15 \mathrm{mmol} / \mathrm{l}$ and were included in the studies.

The first study examined the time-course of development of nerve blood flux deficit in streptozotocin-diabetes, using untreated control and diabetic rats for time-points over a total of 8 weeks.

The aim of the second experiment was to determine the effect of treatment with insulin on diabetes-induced changes in nerve blood flux. The control group and one group of diabetic rats were left untreated. Immediately after confirmation of diabetes, in a second group of diabetic rats, two sustained release insulin implants (Linplant; Møllegaard, Ejby, Denmark; release rate 2 IU/day/implant for more than 40 days), were inserted subcutaneously, under halothane anaesthesia, in the back of the neck of each rat. Blood glucose concentration was measured at least weekly and in the second week of the study a 24-h blood glucose profile was monitored in two parts separated by 5 days.

The third study used BB non-diabetic and diabetic rats, with mean ( \pm SD) age at death of $151 \pm 41$ and $132 \pm 31$ days, respectively. Diabetic animals had a mean $( \pm S D)$ duration of diabetes of $45 \pm 25$ days and had been maintained throughout the protocol on a thrice-weekly insulin regime, using a long-acting heattreated Ultralente preparation (Novo Industri $\mathrm{A} / \mathrm{S}$, Copenhagen, Denmark) [15] designed for minimal glycaemic control.
All rats were weighed at least weekly. Immediately prior to experiment, blood glucose levels were again tested. After death, whole blood and plasma samples were collected for later determination of glycated haemoglobin levels and glucose content, by spectrophotometric assay (GOD-PERID test; Boehringer Mannheim), respectively.

\section{Sciatic nerve Doppler flux}

Animals were anaesthetised initially with halothane $\left(4 \%\right.$ in $\mathrm{O}_{2}$ for induction, $2-2.5 \%$ for maintenance) and a left jugular venous catheter inserted for infusion of alphaxalone $9 \mathrm{mg} / \mathrm{ml}$ and alphadolone acetate $3 \mathrm{mg} / \mathrm{ml}$ (Saffan; Pitman-Moore Ltd, Uxbridge, UK). The manufacturer's solution was diluted $1: 3$ with $0.9 \%$ $\mathrm{NaCl}$ and an initial dose of $4 \mathrm{mg} / \mathrm{kg}$ body weight of this dilution was given on removal of the rats from the halothane source; the solution was infused slowly as the halothane was breathed off. Anaesthesia was maintained by continuous infusion of a $1: 6$ solution of alphaxalone/alphadolone at a rate of $12 \mathrm{mg} / \mathrm{h}$. The left carotid artery was cannulated (PVCIntravenous Cannula-outer diameter $1.34 \mathrm{~mm}$, inner diameter $1.00 \mathrm{~mm}$; Portex, Hythe, UK) and connected to a transducer (Type 4-327 L221; Bell \& Howell, Basingstoke, UK) for measurement of systemic arterial pressure and heart rate. Via a small incision in the left flank the sciatic nerve was exposed. A fibre optic flow probe (Type P4; tip diameter $0.85 \mathrm{~mm}$; Moor Instruments, Axminster, UK) was manoeuvred using a X-Y-Z micropositioner (Prior Scientific Instruments, Bishop's Stortford, UK) untilit was just in contact with the nerve and Doppler flux was registered on the flow monitor (Type MBF3D; Moor Instruments). Measurements were made from each nerve by withdrawal and repositioning of the probe between each. This was repeated until three measurements of similar proportions were obtained (in practice these were usually the first and only three). Both systemic pressure and nerve blood flux outputs were amplified via a MacLab Bridge Amp (AD Instruments Ltd., London, UK), digitized (MacLab/8 Interface Module; AD Instruments), displayed and recorded simultaneously using MacLab "Chart" software (AD Instruments) with a Macintosh personal computer and monitor (supplied as above). Values for all cardiovascular variables were averaged over a 2-min recording period. Body temperature for all rats was maintained at $37.7 \pm 0.5^{\circ} \mathrm{C}$ via homeothermic blanket (Harvard Apparatus Ltd., Edenbridge, UK), with biofeedback by rectal probe. Rats were killed without recovery from anaesthesia.

\section{Statistical analysis}

Data are presented as mean \pm 1 SD. For the insulin study, statistical analyses were carried out by one way analysis of variance (ANOVA). Where the $\mathrm{F}$ ratio gave $p<0.05$, and where there was homogeneity of variance (Cochrans \& Bartlett Box, $p>0.05$ ), comparisons between individual group means were made using Duncan's Multiple Range Test at significance levels of $p<0.05$ and $p<0.01$. Diabetic BB rats were compared with their controls by unpaired $t$-test.

\section{Results}

\section{Animals}

In the time-course study, immediately following streptozotocin injection rats lost weight and were hyperglycaemic; the severity of the diabetic state in these ani- 
mals progressed with time, as illustrated by the trends shown in Figure 1. Final body weights were (mean $\pm 1 \mathrm{SD}) 467 \pm 79 \mathrm{~g}$ for control rats and $325 \pm 40 \mathrm{~g}$ for diabetic rats. At the end of protocols in the other studies, untreated streptozotocin-diabetic rats and diabetic BB rats had characteristically reduced body weights, together with elevated blood glucose, plasma glucose and glycated haemoglobin levels, compared to their respective controls (Table 1). In Study 2, treatment of diabetic animals with insulin prevented these anomalies (Table 1).

\section{Efficacy of insulin treatment}

The strict glycaemic control obtained with insulin implants in diabetic animals was demonstrated by the comparison of insulin-treated diabetic rats with controls, showing similar final weights, plasma glucose and glycated haemoglobin levels (Table 1) and by the narrow range of blood glucose values measured throughout a typical 24-h period (Fig. 2).

\section{Sciatic nerve Doppler flux}

Study 1. Individual nerve Doppler flux and heart rate values for rats in the time-course study are shown in Figure 1. Nerve fluxes in control animals fell only slightly over the 8-week protocol. In diabetic animals, nerve Doppler flux was variable during the 2 days after streptozotocin injection; however, from day 4 , when the flux in diabetic rats was $80 \%$ of control, measurements fell steadily and appeared to plateau at $40 \%$ of control values after 4 weeks of diabetes. Mean arterial pressures of control and diabetic animals were not different (mean $\pm 1 \mathrm{SD}$ in $\mathrm{mm} \mathrm{Hg}$ were $107 \pm 11$ and $110 \pm 9$, respectively). From day 4, heart rates of diabetic animals were reduced when com- pared to those of controls, although, after 8 weeks of diabetes, differences between these groups were not seen.

Study 2. Figure 3 shows individual animal data points with group means \pm 1 SD from this study. A $66 \%$ reduction in Doppler flux was seen in sciatic nerves of untreated diabetic animals compared to those of controls. Fluxes in nerves of insulin-treated diabetic rats were only marginally lower than those of the control group (91\% of control mean and the difference was not significantly different), indicating substantial prevention of the diabetes-associated decrease. There were no differences between group mean arterial pressures
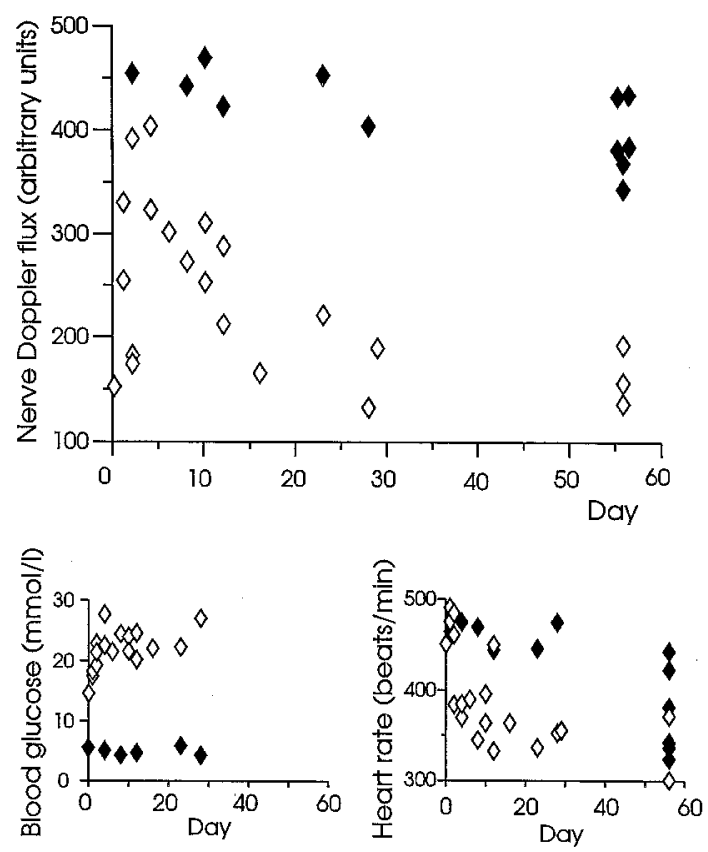

Fig. 1. Time course of development of changes in nerve laser Doppler flux, blood glucose and heart rate in diabetes. Individual points show values for each rat. Control rats, $\diamond$; diabetic rats, $\diamond$

Table 1. Body weight, final plasma glucose, glycated haemoglobin, mean arterial pressure, heart rate and sciatic nerve Doppler flux from the insulin study (Study 2) and from the comparison of control and diabetic BB rats (Study 3)

\begin{tabular}{|c|c|c|c|c|c|c|c|}
\hline & \multicolumn{2}{|c|}{ Body weight (g) } & \multirow{2}{*}{$\begin{array}{l}\text { Plasma } \\
\text { glucose } \\
(\mathrm{mmol} / \mathrm{l})\end{array}$} & \multirow{2}{*}{$\begin{array}{l}\text { Glycated } \\
\text { haemoglo- } \\
\text { bin }(\%)\end{array}$} & \multirow{2}{*}{$\begin{array}{l}\text { Mean arterial } \\
\text { pressure } \\
(\mathrm{mmHg})\end{array}$} & \multirow{2}{*}{$\begin{array}{l}\text { Heart rate } \\
\text { (beats/min) }\end{array}$} & \multirow{2}{*}{$\begin{array}{l}\text { Nerve Dopp- } \\
\text { ler flux (arbi- } \\
\text { trary units) }\end{array}$} \\
\hline & Initial & Final & & & & & \\
\hline Study 2 & & & & & & & \\
\hline Control (10) & $\begin{array}{l}321 \pm 19 \\
\text { NS }\end{array}$ & $\begin{array}{l}455 \pm 31 \\
p<0.01\end{array}$ & $\begin{array}{c}8.6 \pm 0.9 \\
p<0.01\end{array}$ & $\begin{array}{l}3.7 \pm 0.7 \\
p<0.01\end{array}$ & $\begin{array}{l}114 \pm 5.9 \\
\text { NS }\end{array}$ & $\begin{array}{l}426 \pm 97 \\
\text { NS }\end{array}$ & $\begin{array}{l}435 \pm 53 \\
p<0.01\end{array}$ \\
\hline Diabetic (9) & $\begin{array}{l}321 \pm 19 \\
\text { NS }\end{array}$ & $\begin{array}{l}361 \pm 38 \\
p<0.05\end{array}$ & $\begin{array}{l}33.4 \pm 6.7 \\
p<0.01\end{array}$ & $\begin{array}{l}7.5 \pm 1.9 \\
p<0.01\end{array}$ & $\begin{array}{l}112 \pm 6.4 \\
\text { NS }\end{array}$ & $\begin{array}{l}355 \pm 84 \\
p<0.05\end{array}$ & $\begin{array}{l}193 \pm 62 \\
p<0.01\end{array}$ \\
\hline Diabetic-insulin (10) & $322 \pm 17$ & $419 \pm 99$ & $8.0 \pm 5.5$ & $4.3 \pm 0.7$ & $109 \pm 13.6$ & $479 \pm 128$ & $396 \pm 62$ \\
\hline $\begin{array}{l}\text { Study } 3 \\
\text { Control BB (11) }\end{array}$ & NM & $\begin{array}{l}344 \pm 95 \\
p<0.05\end{array}$ & $\begin{array}{c}8.2 \pm 1.6 \\
p<0.01\end{array}$ & $\begin{array}{l}4.0 \pm 1.2 \\
p<0.05\end{array}$ & $\begin{array}{l}108 \pm 11 \\
\text { NS }\end{array}$ & $\begin{array}{l}329 \pm 62 \\
\text { NS }\end{array}$ & $\begin{array}{l}336 \pm 118 \\
p<0.01\end{array}$ \\
\hline Diabetic BB (8) & NM & $269 \pm 39$ & $30.5 \pm 4.3$ & $7.3 \pm 1.8$ & $106 \pm 11$ & $296 \pm 40$ & $190 \pm 53$ \\
\hline
\end{tabular}

Data are mean $\pm 1 \mathrm{SD}$; numbers of rats are in parentheses. Data from Study 2 were analysed by one-way analysis of variance with Duncan's multiple range tests. Study 3 data were compared (control vs diabetic) by unpaired $t$-tests. All $p$ values indicate differences between data immediately above and below. NS, Not significant; NM, not measured 


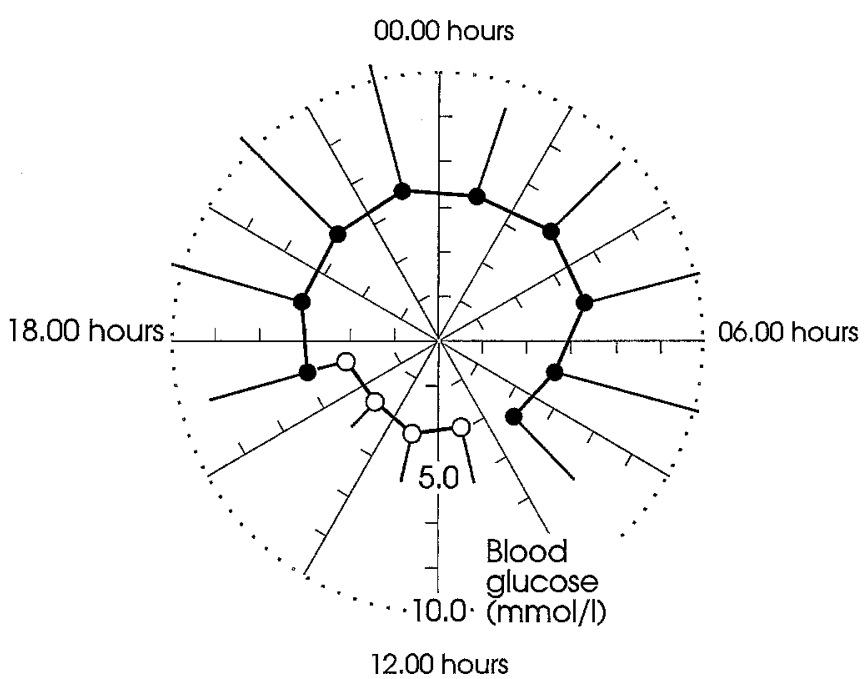

Fig. 2. Twenty-four hour profiles of blood glucose in the group of streptozotocin-diabetic rats given sustained insulin delivery implants. represent a continuous set of data obtained over one night; $O$ represent daytime data obtained 5 days later. Upper limit bars represent calculated standard deviations, though since the data were clearly positively skewed, they are included only to give a rough indication of scatter

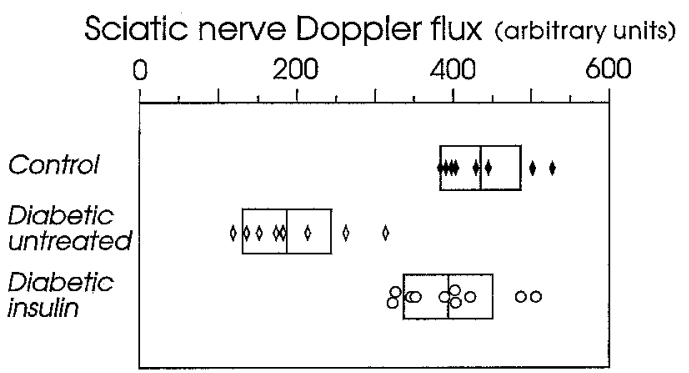

Fig.3. Effects of diabetes and of treatment with insulin on sciatic nerve laser Doppler flux. Individual points show nerve Doppler flux for each rat, bars indicate group means and boxes show $\pm 1 \mathrm{SD}$

(Table 1). Heart rates of control and insulin-treated diabetic animals were higher than those of the remaining diabetic groups (Table 1).

Study 3. Group means \pm 1 SD for nerve Doppler flux, mean arterial pressure and heart rate for $\mathrm{BB}$ rats are shown in Table 1. Fluxes for diabetic rats were similar to those found in animals with 2 to 8 weeks of streptozotocin-diabetes and were $57 \%$ of their respective control levels. The mean nerve Doppler flux for nondiabetic BB rats was slightly lower than that registered in control Wistar animals. Mean heart rate was again numerically lower in the diabetic group, when compared to controls, but the difference was not significant. There were no differences in group mean arterial pressures.

\section{Discussion}

Untreated streptozotocin-injected rats suffered weight loss, hyperglycaemia and raised levels of glycated haemoglobin, characteristic of experimental Type 1 (insulin-dependent) diabetes. The spontaneously diabetic BB rats also showed reduced body weight and increased levels of both plasma glucose and glycated haemoglobin, when compared to their controls. Insulin delivery reduced the severity of the diabetic state in streptozotocin-treated rats, as indicated by attenuation of the body weight change and normalisation of plasma glucose and glycated haemoglobin levels.

The time-course study indicated that deficits in nerve Doppler flux of streptozotocin-diabetic rats, compared to control animals, are evident within a week following induction of the disease, progress over the next 3 weeks, form a plateau at about $40 \%$ of control values after 4 weeks and are sustained at this level for at least another 4 weeks. Cameron et al. [7] also found early changes in sciatic nerve blood flow, albeit endoneurial flow, of diabetic rats, as measured by hydrogen clearance. After 1 week of diabetes, blood flow reductions were slightly larger ( $59 \%$ of control values) than those found in the present study, but remained at this level for 4 months. The hydrogen clearance technique may underestimate reductions in flow, due to diffusion of gas from the nerve during measurement [7], which would account for the relatively larger changes in streptozotocin-diabetes seen at later time-points in the present study. Data from both the time-course and insulin studies, after 4 and 8 weeks of diabetes, show marked reductions in fluxes of untreated diabetic animals, compared to controls; this is consistent with a mean flux of $47 \%$ of the control mean, in 5-week diabetic animals found in a previous study [14]. Similar reductions after 1 or more months of streptozotocin-diabetes in rats have also been found using laser Doppler velocimetry [16] and other techniques for measuring both endoneurial and whole nerve blood flow [6,17-20], although, as mentioned, those determined by hydrogen clearance may underestimate differences. One group failed to find reduced nerve blood flow in diabetic animals, using hydrogen clearance [21], although an explanation for this is unclear. It should also be noted that, in contrast to other studies, Corbett et al [22] and Sutera et al. [23], using radiolabelled microspheres to determine nerve perfusion, consistently found increases in flow in nerves of diabetic rats, compared to controls. This may reflect accumulation of label in vessels, normally of greater diameter than the microspheres, because of vascular compression due to the reported expansion of endoneurial space in experimental diabetes [24].

The limitations of laser Doppler flux measurements as parameters of nerve blood flow were discussed in detail in our previous study [14], but some further consideration should be given here. Nerve Doppler flux readings are not direct measures of blood flow but are 
dependent on the number and velocity of erythrocytes passing the probe and, therefore, give an index of whole blood flow. This method does not, therefore, give absolute flow values, nor can flow between nerve compartments be distinguished. Other studies have, however, demonstrated linear correlations of this method with hydrogen clearance [25] and iodo$\left[{ }^{14} \mathrm{C}\right]$ antipyrine [26] methods for measuring nerve blood flow at steady state. Laser Doppler velocimetry is therefore recommended for relative estimations of nerve blood flow [25], especially in disease states [26]. We suggest, therefore, that observed reductions in Doppler flux in nerves of diabetic animals, compared to those of controls, are indicative of reduced sciatic nerve blood flow. We cannot discriminate between epineurial and endoneurial vessels, but, as endoneurial flow accounts for approximately $50 \%$ of whole nerve flow [26] and is primarily delivered via epineurial vessels [27], reductions approaching $60 \%$ in short-term diabetic rats, relative to controls, are unlikely to be due solely to lowered epineurial flow. It is, therefore, logical to suggest that the data reflect deficits in sciatic nerve blood flow in streptozotocin-diabetic animals and that decreases in endoneurial nutritive flow may have contributed. The magnitude of changes in nerve flux in experimental diabetes are, thus, likely to indicate debilitating ischaemia. This is supported by the exaggerated resistance to ischaemic conduction block and reduced nerve oxygen tension of diabetic animals $[6,28]$ and may contribute to their slowed conduction $[1,29]$. It is possible that nerve laser Doppler velocimetry overestimates diabetes-associated deficits in flow because of its dependence on movement of erythrocytes, which are poorly deformable in this disease [30].

Nerve fluxes of control animals fell only slightly over the 8 weeks of the time-course study, although body weight progressively increased (data not shown). Such a decline was not evident in another study, which used older animals for an extended protocol period [7]. It is, thus, unlikely that Doppler flux is related to body weight, which may have artifactually resulted in deficient nerve fluxes of the smaller diabetic animals. Of interest, Kihara et al. [31] have reported that nerve blood flow declines with increasing age due to reduced microvascular calibre, although this effect occurred over a longer time-course than that of the control animals used in this study.

Tight glycaemic control of streptozotocin-diabetic rats with insulin implants prevented the diabetes-induced deficit in nerve Doppler flux and we suggest that this was due to amelioration of the diabetic state. We should state that the respective roles of prevention of hyperglycaemia or of hypoinsulinaemia per se by insulin treatment are not defined. Cameron et al. [7] have reported reductions in nerve blood flow of rats made hyperglycaemic by glucose infusion which were similar to those of streptozotocin-diabetic animals, indicating hyperglycaemia as a primary cause.
Our final study reported decreased nerve fluxes in 6week diabetic BB rats, relative to their controls, which was of slightly increased proportions compared to the changes seen in 4-week streptozotocin-diabetes. This indicates the presence of peripheral nerve ischaemia in this model of Type 1 diabetes, albeit of a lesser degree than that found in acute streptozotocin-diabetes. Although, to our knowledge, nerve blood flow of spontaneously diabetic BB rats has not previously been measured, the finding is consistent with reported nerve conduction abnormalities of these animals, similar to those of streptozotocin-diabetic rats [32].

Systemic arterial pressures did not vary between groups suggesting that changes in sciatic nerve Doppler flux were due to local vasomotor anomalies in diabetes. These could include altered release of cyclooxygenase products and nitric oxide - phenomena which have both been demonstrated in experimental diabetes [33, 34]. Heart rates of control and insulin-treated diabetic animals were consistently higher than those of respective groups of diabetic rats. Bradycardia of streptozotocin-diabetic rats has repeatedly been reported and may reflect disturbances of cardiac autonomic innervation $[35,36]$ or altered pacemaker potentials due, perhaps, to deficient $\mathrm{Na}^{+} / \mathrm{K}^{+}$-ATPase activity $[37,38]$. However, as arterial pressures in diabetic animals did not differ from control values, it is unlikely that the diabetes-induced reductions in peripheral nerve blood flux resulted from a general vascular insufficiency.

In summary, we suggest that reduced nerve Doppler flux seen in short-term diabetic animals reflects defective nerve blood supply, indicative of an ischaemia, which occurs in both the streptozotocin- and spontaneously-diabetic (BB) rat. In streptozotocin diabetes, neurovascular insufficiency presents within a week of onset of the disease, forms a plateau after 4 weeks and is maintained for at least 2 months. The data indicate that intensive treatment with insulin can prevent nerve ischaemia.

Acknowledgements. We thank Dr. J. Marshall for advice on anaesthesia using Saffan. EJS was supported by a grant from the William Harvey Research Institute, made possible by a donation from Ono Pharmaceuticals Ltd., and ALC was supported by a British Heart Foundation Project Grant awarded to DRT.

\section{References}

1. Carrington AL, Ettlinger CB, Calcutt NA, Tomlinson DR (1991) Aldose reductase inhibition with imirestat-effects on impulse conduction and insulin-stimulation of $\mathrm{Na}^{+} / \mathrm{K}^{+}-$ adenosine triphosphatase activity in sciatic nerves of streptozotocin-diabetic rats. Diabetologia 34: 397-401

2. Pirart J (1978) Diabetes mellitus and its degenerative complications; a prospective study of 4400 patients observed between 1947 and 1973. Part 1. Diabetes Care 1: 168-188

3. Pirart J (1978) Diabetes mellitus and its degenerative complications: a prospective study of 4400 patients observed between 1947 and 1973. Part 2. Diabetes Care 1:252-263 
4. Jennings PE, Barnett AH (1988) New approaches to the pathogenesis and treatment of diabetic microangiopathy. Diab Med 5: 111-117

5. Tomlinson DR, Willars GB, Carrington AL (1992) Aldose reductase inhibitors and diabetic complications. Pharmacol Ther 54: 151-194

6. Tuck RR, Schmelzer JD, Low PA (1984) Endoneurial blood flow and oxygen tension in the sciatic nerves of rats with experimental diabetic neuropathy. Brain 107: 935-950

7. Cameron NE, Cotter MA, Low PA (1991) Nerve blood flow in early experimental diabetes in rats: relation to conduction deficits. Am J Physiol 261: E1-E8

8. Newrick PG, Wilson AJ, Jakubowski JA, Boulton AJM, Ward JD (1986) Sural nerve oxygen tension in diabetes. BMT 293: 1053-1054

9. Smith WJ, Diemel LT, Leach RM, Tomlinson DR (1991) Central hypoxaemia in rats provokes neurological defects similar to those seen in experimental diabetes mellitus: evidence for a partial role of endoneurial hypoxia in diabetic neuropathy. Neuroscience 45: 255-259

10. Cameron NE, Cotter MA, Robertson S (1992) Angiotensin converting enzyme inhibition prevents development of muscle and nerve dysfunction and stimulates angiogenesis in streptozotocin-diabetic rats. Diabetologia 35: 12-18

11. Cameron NE, Cotter MA, Ferguson K, Robertson S, Radcliffe MA (1991) Effects of chronic $\alpha$-adrenergic receptor blockade on peripheral nerve conduction, hypoxic resistance, polyols, $\mathrm{Na}^{+}-\mathrm{K}^{+}$-ATPase activity, and vascular supply in STZ-D rats. Diabetes 40: $1652-1658$

12. Cameron NE, Cotter MA, Robertson S (1991) Essential fatty acid diet supplementation: effects on peripheral nerve and skeletal muscle function and capillarization in streptozocin-induced diabetic rats. Diabetes 40: 532-539

13. Lockett MJ, Tomlinson DR (1992) The effects of dietary treatment with essential fatty acids on sciatic nerve conduction and activity of the $\mathrm{Na}^{+}-\mathrm{K}^{+}$pump in streptozotocindiabetic rats. Br J Pharmacol 105: 355-360

14. Stevens EJ, Lockett MJ, Carrington AL, Tomlinson DR (1993) Essential fatty acid treatment prevents nerve ischaemia and associated conduction anomalies in rats with experimental diabetes mellitus. Diabetologia 36: 397-401

15. Rasch R (1979) Control of blood glucose levels in the streptozotocin diabetic rat using a long-acting heat-treated insulin. Diabetologia 16: 185-190

16. Yasuda H, Sonobe M, Yamashita M et al. (1989) Effect of prostaglandin $\mathrm{E}_{1}$ analogue TFC 612 on diabetic neuropathy in streptozocin-induced diabetic rats: comparison with aldose reductase inhibitor ONO 2235. Diabetes 38: 832-838

17. Hotta N, Kakuta H, Fukasawa Het al. (1992) Effect of niceritrol on streptozocin-induced diabetic neuropathy in rats. Diabetes 41: 587-591

18. Kihara M, Schmelzer JD, Poduslo JF, Curran GL, Nickander KK, Low PA (1991) Aminoguanidine effects on nerve blood flow, vascular permeability, electrophysiology, and oxygen free radicals. Proc Natl Acad Sci USA 88: 6107-6111

19. Low PA, Tuck RR, Dyck PJ, Schmelzer JD, Yao JK (1984) Prevention of some electrophysiologic and biochemical abnormalities with oxygen supplementation in experimental diabetic neuropathy. Proc Natl Acad Sci USA 81: 6894-6898

20. Monafo WW, Eliasson SG, Shimazaki S, Sugimoto H (1988) Regional blood flow in resting and stimulated sciatic nerve of diabetic rats. Exp Neurol 99: 607-614
21. Zochodne DW, Ho LT (1992) Normal blood flow but lower oxygen tension in diabetes of young rats: microenvironment and the influence of sympathectomy. Can J Physiol Pharmacol 70: 651-659

22. Corbett JA, Tilton RG, Chang K et al. (1992) Aminoguanidine, a novel inhibitor of nitric oxide formation, prevents diabetic vascular dysfunction. Diabetes 41: 552-556

23. Sutera SP, Chang K, Marvel J, Williamson JR (1992) Concurrent increases in regional hematocrit and blood flow in diabetic rats: prevention by sorbinil. Am J Physiol Heart Circ Physiol 263: H945-H950

24. Jakobsen J (1978) Peripheral nerves in early experimental diabetes. Diabetologia 14: 113-119

25. Takeuchi M, Low PA (1987) Dynamic peripheral nerve metabolic and vascular responses to exsanguination. Am J Physiol 253: E349-E353

26. Rundquist I, Smith QR, Michel ME, Ask P, Oberg PA, Rapoport SI (1985) Sciatic nerve blood flow measured by laser Doppler flowmetry and [14C]iodoantipyrine. Am J Physiol 248: 311-317

27. Lundborg G, Branemark P-I (1968) Microvascular function and structure of peripheral nerves. Adv Microcirc 1: 66-75

28. Calcutt NA, Ettlinger CB, Carrington AL, Diemel LT, Tomlinson DR (1991) Resistance to hypoxic conduction block in sciatic nerves of rats with streptozotocin-induced diabetes. J Neurol Sci 103: 116-123

29. Cameron NE, Cotter MA, Robertson S, Maxfield EK (1993) Nerve function in experimental diabetes in rats: effects of electrical stimulation. Am J Physiol Endocrinol Metab 264: E161-E166

30. McMillan DE (1983) The effect of diabetes on blood flow properties. Diabetes 32: 56-63

31. Kihara M, Nickander KK, Low PA (1991) The effect of aging on endoneurial blood flow, hyperemic response and oxygenfree radicals in rat sciatic nerve. Brain Res 562: 1-5

32. MendeIl JR, Sahenk Z, Warmolts JR, Marshall JK, Thibert P (1981) The spontaneously diabetic BB Wistar rat. Morphologic and physiologic studies of peripheral nerve. J Neurol Sci 52: $103-115$

33. Ward KK, Low PA, Schmelzer JD, Zochodne DW (1989) Prostacyclin and noradrenaline in peripheral nerve of chronic experimental diabetes in rats. Brain 112:197-208

34. Kamata K, Miyata N, Kasuya Y (1989) Impairment of endothelium-dependent relaxation and changes in levels of cyclic GMP in aorta from streptozotocin-induced diabetic rats. Br J Pharmacol 97: 614-618

35. Tomlinson KC, Gardiner SM, Bennett T (1990) Blood pressure in streptozotocin-treated Brattleboro and Long-Evans rats. Am J Physiol 258: R852-R859

36. Tomlinson KC, Gardiner SM, Hebden RA, Bennett T (1992) Functional consequences of streptozotocin-induced diabetes mellitus, with particular reference to the cardiovascular system. Pharmacol Rev 44: 103-150

37. Foy JM, Lucas PD (1978) Comparison between spontaneously beating atria from control and streptozotocindiabetic rats. J Pharm Pharmac 30: 558-562

38. Pierce GN, Dhalla NS (1983) Sarcolemmal Na + -K + -ATPase activity in diabetic rat heart. Am J Physiol 245: C241$\mathrm{C} 247$ 